\title{
PENGARUH KOMUNIKASI DAN HUBUNGAN INDUSTRIAL TERHADAP KEPUASAN KERJA KARYAWAN PADA HOTEL FAVE PETITENGET KABUPATEN BADUNG BALI
}

\author{
I Ketut Merta ${ }^{1}$ \\ Anak Agung Elik Astari ${ }^{2}$ \\ Ni Kadek Ernawati Kertagam ${ }^{3}$ \\ Progrma Studi Management, Fakultas Ekonomi, Universitas Mahendradatta, \\ Jl. Ken Arok No.12, Peguyangan, Denpasar Utara, Kota Denpasar, Bali 80115 \\ ${ }^{1}$ Email : iketutmerta2270@gmail.com \\ ${ }^{2}$ Email : elik.adoenku@gmail.com
}

\begin{abstract}
Absrtrak - Pada hasil penelitian, analisis dan pembahasan mengenai masalah pengaruh antara variabel independent dan dependent dengan menggunakan metodelogi analisis regresi berganda, jumlah responden 78 orang dari jumlah keseluruhan populasi, dapat dijelaskan sebagai berikut: Variabel Komunikasi (X1) secara parsial berpengaruh signifikan terhadap variabel Kepuasan kerja karyawan (Y). Dengan uji t pada variabel Komunikasi menghasilkan: t hitung sebesar 3.202 dan signifikansi sebesar 0,002. $t$ hitung 3.202 > t tabel yang nilainya 1,663 dengan tingkat signifikansi $0,173>0,05$, maka dapat diketahui bahwa hipotesis yang menyatakan Komunikasi berpengaruh positif signifikan terhadap kepuasan kerja karyawan. Sehinga komunikasi mengambil peran yang doniman dalam kepuasan kerja karyawan .Variabel Hubungan Industrial (X2) secara parsial signifikan menghasil t hitung sebesar 5.349 dan signifikansi sebesar 0,000. $t$ hitung $5.349>\mathrm{t}$ tabel yang nilainya 1,663 dengan tingkat signifikansi $0,173>0,05$, maka dapat diketahui bahwa hipotesis yang menyatakan hubungan industrial berpengaruh positif signifikan terhadap kepuasan kerja karyawan, hal ini membuktikan hubungan industrial berjalan harmonis.. Hipotesi diterima dengan t hitung $1.377>$ $\mathrm{t}$ tabel 0,663 , maka hipotesis yang menyatakan adanya pengaruh yang positif signifikan antara Komunikasi dan hubungan industrial dengan Kepuasan kerja karywan. Dengan baiknya hubungan ke dua variabel sehingga kepuasan kerja karyawan dapat berjalan dengan baik,Penelitian lebih lanjut dapat dilakukan pada kesempatan lain dengan variabel diluar penelitian ini.
\end{abstract}

Kata Kunci: Komunikasi, Hubungan Industrial dan Kepuasan Kerja Karyawan 
Abstract- In the research result, analysis and discussion about the problem of influence between independent variable and dependent by using methodology of multiple regression analysis, the number of respondents 78 people from the total population, can be explained as follows: Communication Variables (X1) partially significant effect on variable Satisfaction employee work $(Y)$. With the t test on the Communication variable produces: $t$ count of 3.202 and significance of 0.002. $t$ arithmetic 3.202> t table whose value is 1.663 with significance level 0.173>0.05, it can be seen that the hypothesis that Communications have a significant positive effect on employee job satisfaction. So that communication take the role of doniman in employee job satisfaction. Variable of Industrial Relations (X2) partially significant result t count equal to 5,349 and significance equal to 0,000. $t$ count $5.349>$ t table whose value is 1.663 with significance level $0.173>0.05$, it can be seen that the hypothesis expressing industrial relations have a significant positive effect on employee job satisfaction, this proves industrial relations run harmonious .. Hypothesis accepted by $t$ arithmetic $1.377>t$ table 0.663, then the hypothesis which states that there is a significant positive influence between communication and industrial relations with employee job satisfaction. With the good relationship to the two variables so that employee job satisfaction can run well, further research can be done on other occasions with variables outside this research.

Keywords: Communication, Industrial Relations and Employee Job Satisfaction 


\section{PENDAHULUAN}

Perkembangan dunia usaha khususnya dibidang akomodasi pariwisata seperti penginapan di Bali ini dirasakan semakin maju dan semakin pesat yang membawa dampak pada persaingan yang semakin kompetitif. Situasi seperti ini menyebabkan pimpinan dan karyawan perusahaan, khususnya tempat penginapan dituntut untuk selalu bertindak secara profesional dan terorganisir dalam mencapai tujuan perusahaan.Setiap perusahaan yang didirikan umumnya mempunyai tujuan untuk memaksimalkan nilai perusahaan bagi pemiliknya agar mendapatkan tingkat keuntungan yang maksimal dalam mempertahankan kelangsungan hidup perusahaan. Tujuan ini akan tercapai dengan perkembangan kinerja sumber daya manusia yang lebih terampil melalui perencanaan, pengorganisasian, pengarahan dan pengawasan yang baik sehingga perusahaan akan dapat berjalan sesuai dengan apa yang telah direncanakan.

Daerah Bali yang ditetapkan sebagai pusat pariwisata di Indonesia bagian tengah merupakan daerah wisata yang tidak saja terkenal dengan keramah tamahan penduduknya, adat istiadatnya, alamnya yang indah, atraksi wisata serta mempunyai keaneka ragaman kebudayaan masing-masing daerah yang ada di Bali. Keadaan ini membuka peluang bagi industri pariwisata untuk lebih berkembang dan mampu menyediakan lapangan pekerjaan dan menyerap tenaga kerja serta mampu mendatangkan devisa bagi Negara.

Sumber daya manusia (SDM) adalah faktor sentral dalam suatu organisasi.Apapun bentuk serta tujuannya, organisasi dibuat berdasarkan visi untuk kepentingan manusia dan dalam pelaksanaan misinya dikelola dan diurus oleh manusia. Jadi, manusia merupakan faktor strategis dalam semua kegiatan organisasi atau dengan kata lain manusia merupakan kekayaan (asset) yang paling utama yang dimiliki oleh suatu organisasi (Yuniarsih dan Suwatno, 2017 : 8). Apapun bentuk serta tujuannya, organisasi dibuat berdasarkan visi untuk kepentingan manusia dan dalam pelaksanaan misinya dikelola dan diurus oleh manusia. Jadi manusia merupakan faktor strategis dalam semua kegiatan organisasi. Dengan demikian sudah selayaknya karyawan diperlukan secara layak dan adil sesuai dengan apa yang telah diberikan kepada perusahaan, yang dapat berimplikasi kepada meningkatnya kepuasan kerja karyawannya.

Pada beberapa kasus dalam hubungan industrial sering kali terlihat perlawanan antara karyawan dan manajemen yang berujung pemogokan. Hal ini bisa terjadi karena ketidakpuasan, sebagaimana diungkapkan Wexley dan Yukl (2005 : 157) dalam Emron (2017 : 207) bahwa, frustasi yang menyertai ketidakpuasan kerja dapat mengarah pada perilaku agresif daripada penarikan diri. Tindakan agresif dapat berbentuk sabotase, sengaja melakukan kesalahan, serta kegiatankegiatan serikat buruh yang militan 
seperti pemogokan yang tidak bertanggung jawab, perlambatan kerja, serta proses yang berlebihan. Jadi, banyak terjadi pertengkaran dan permusuhan di antara pekerja ketika mereka sangat frustasi. Bila tindakan agresif mencampuri jalannya pekerjaan, menurunkan kualitas produksi, serta melarang bekerja sama dan berkelompok, mereka akan menunjukkan biaya yang mahal bagi organisasi.

Dalam organisasi, komunikasi merupakan hal yang penting, karena tanpa adanya komunikasi organisasi tidak dapat berjalan. Begitu pula dengan komunikasi, bila dalam organisasi komunikasinya kurang baik akan berdampak efektivitas organisasi. Komunikasi adalah sebuah proses dua arah yang memberikan kesempatan kepada orang yang berkomunikasi untuk merespon dan juga menyampaikan pesan-pesan (Winardi, 2016 : 165). Dalam situasi tertentu pula komunikasi dimaksudkan untuk merubah sikap atau tingkah laku seseorang atau sejumlah orang sehingga ada efek tertentu yang diharapkan, dalam hal ini salah satunya adalah kepuasan kerja karyawan.Dapat dikatakan adanya komunikasi yang baik sangat menentukan kepuasan kerja karyawannya.

Salah satu segi hubungan antara organisasi dengan para anggotanya menyangkut apa yang lazim dikenal dengan istilah hubungan industrial. Pemeliharaan hubungan industrial dalam rangka keseluruhan proses manajemen sumber daya manusia berkisar pada pemikiran bahwa hubungan yang serasi dan harmonis antara manajemen dengan para pekerja yang terdapat dalam organisasi mutlak perlu ditumbuhkan, dijaga dan dipelihara demi kepentingan semua pihak yang telah mempertaruhkan kepentingannya dalam organisasi. Kekurangberhasilan memelihara hubungan yang serasi dan harmonis itu akan merugikan banyak pihak dan tidak terbatas hanya pada pihak manajemen dan para pekerja saja (Siagian, $2016: 327$ ).

Hotel Fave Petitenget

Kabupaten Badung sebagai tempat penelitian merupakan salah satu hotel bintang empat di Kabupaten Badung yang sedang berbaur dalam persaingan dengan usaha sejenis khususnya di kawasan Petitenget. Jumlah kamar Hotel Fave Petitenget Kabupaten Badung sebanyak 55 unit dengan jumlah karyawan adalah 78 orang, termasuk satu orang general manager selaku top management (pimpinan manajemen puncak). Kegiatan karyawan pada Hotel Fave Petitenget Kabupaten Badung sebagian besar secara langsung berhubungan dengan wisatawan yang berkunjung dan menginap, maka sudah selayaknya karyawan memberikan pelayanan yang terbaik kepada wisatawan.

Hotel Fave Petitenget

Kabupaten Badung di dalam usaha meningkatkan kepuasan kerja karyawan, harus dapat memperhatikan terhadap faktorfaktor yang mempengaruhi kepuasan kerja karyawan, seperti halnya menurut Rivai (2016 : 452) antara lain, kompensasi finansial, 
kepemimpinan, pendidikan dan pelatihan, partisipasi, lingkungan kerja, komunikasi dan hubungan industrial. Berdasarkan kenyataan yang terjadi pada Hotel Fave Petitenget Kabupaten Badung, dapat

\section{Tabel 1}

Jenis Pertemuan, Frekuensi dan Bentuk Komunikasi Formal Pada Hotel Fave Petitenget Kabupaten Badung

Tahun 2017

\begin{tabular}{|c|c|c|c|c|}
\hline $\begin{array}{l}\mathbf{N} \\
\mathbf{0}\end{array}$ & Jenis Pertemuan & $\begin{array}{c}\text { Frekuensi } \\
\text { Pertemuan }\end{array}$ & $\begin{array}{c}\text { Bentuk } \\
\text { Komunikasi }\end{array}$ & Keterangan \\
\hline 1 & $\begin{array}{l}\text { Pimpinan dengan } \\
\text { kepala bagian } \\
\text { (komunikasi } \\
\text { vertikal) }\end{array}$ & $\begin{array}{l}12 \text { kali per } \\
\text { tahun }\end{array}$ & $\begin{array}{l}\text { a. Ceramah } \\
\text { b. Rapat } \\
\text { berkala }\end{array}$ & $\begin{array}{l}\text { a. Meningkatkan mutu } \\
\text { pelayanan perusahaan } \\
\text { b. Pemecahan masalah } \\
\text { yang timbul dalam } \\
\text { melakukan pekerjaan }\end{array}$ \\
\hline 2 & $\begin{array}{l}\text { Kepala bagian } \\
\text { dengan karyawan } \\
\text { (komunikasi } \\
\text { horizontal) }\end{array}$ & $\begin{array}{l}24 \text { kali per } \\
\text { tahun }\end{array}$ & $\begin{array}{l}\text { a. Rapat } \\
\text { berkala } \\
\text { b. Rapat } \\
\text { kelompok }\end{array}$ & $\begin{array}{l}\text { a. Meningkatkan mutu } \\
\text { pelayanan masing- } \\
\text { masing bagian } \\
\text { b. Meningkatkan kinerja } \\
\text { masing-masing bagian }\end{array}$ \\
\hline 3 & $\begin{array}{l}\text { Kepala bagian } \\
\text { dengan kepala } \\
\text { bagian (komuni- } \\
\text { kasi silang) }\end{array}$ & $\begin{array}{l}4 \text { kali per } \\
\text { tahun }\end{array}$ & $\begin{array}{l}\text { a. Rapat } \\
\text { berkala }\end{array}$ & $\begin{array}{l}\text { a. Meningkatkan } \\
\text { komunikasi dan kerja } \\
\text { sama antar bagian }\end{array}$ \\
\hline
\end{tabular}

Sumber : Hotel Fave Petitenget Kabupaten Badung

Komunikasi yang berjalan selama ini pada Hotel Fave Petitenget Kabupaten Badung meliputi komunikasi formal dan komunikasi informal. Komunikasi yang bersifat formal pada umumnya terjadi pada jam kerja seperti halnya dalam rapat dan pengarahan, sedangkan komunikasi yang bersifat informal biasanya terjadi diluar jam kerja seperti pada saat istirahat maupun saat pulang kerja. Adapun jenis pertemuan, frekuensi dan bentuk komunikasi formal pada Fave Petitenget Kabupaten Badung Tahun 2016 dapat dilihat pada Tabel 1. dapat dijelaskan bahwa komunikasi formal adalah proses komunikasi yang memanfaatkan saluran-saluran formal dalam struktur organisasi. Komunikasi formal yang terjadi pada Hotel Fave Petitenget Kabupaten Badung meliputi komunikasi vertikal, horizontal dan silang.Komunikasi vertikal adalah komunikasi dari pimpinan ke bawahan dan dari bawahan ke pimpinan secara timbal balik.Komunikasi horizontal adalah komunikasi secara mendatar, yaitu komunikasi antara karyawan dengan komunikasi karyawan.Sedangkan diagonal adalah komunikasi secara silang, yaitu komunikasi antara masing-masing 
kepala bagian. Sebaliknya komunikasi non formal adalah proses komunikasi yang dilakukan secara tidak resmi, artinya komunikasi terjadi antara orang yang ada dalam suatu organisasi, akan tetapi tidak direncanakan atau tidak ditentukan dalam struktur.

$$
\text { Dalam organisasi }
$$

komunikasi merupakan hal penting, karena tanpa adanya komunikasi organisasi tidak dapat bisa berjalan. Begitu pula dengan komunikasi, bila dalam organisasi komunikasinya kurang baik akan berdampak pada efektifitas organisasi. Komunikasi adalah sebuah proses dua arah yang memberikan kesempatan kepada orang yang berkomunikasi untuk merespons dan juga menyampaikan pesan-pesan, Denny dalam (Sinta, 2015 : 9). Dalam situasi tertentu pula komunikasi dimaksudkan untuk merubah sikap atau tingkah laku seseorang atau sejumlah orang sehingga ada efek tertentu yang diharapkan, dalam hal ini salah satunya adalah kepuasan kerja karyawan.Dapat dikatakan adanya komunikasi yang baik sangat menentukan kepuasan kerja karyawannya

Beberapa masalah yang terjadi berkaitan dengan komunikasi karyawan pada Hotel Fave Petitenget Kabupaten Badung adalah pimpinan tidak memberikan informasi tentang solusi yang harus dilakukan dalam mengatasi masalah pekerjaan sehingga karyawan maupun kelompok kerjanya kesulitan untuk mengambil keputusan.Selain itu, pimpinan kurang jelas dan tegas dalam mengarahkan karyawan untuk menyelesaikan tugastugas baru yang belum pernah dikerjakan.
Hotel Fave Petitenget Kabupaten Badung selain memperhatikan komunikasi yang terjadi pada perusahaan, juga memperhatikan bagaimana pentingnya hubungan industrial diterapkan dalam perusahaan, dengan harapan tercapai kerjasama yang serasi dan harmonis antar sesama karyawan maupun antara pihak manajemen perusahaan dan karyawan. Kebijakan yang dilakukan manajemen dalam usaha mewujudkan hubungan industrial yang serasi dan harmonis adalah dengan cara :

1. Memberikan kesempatan yang sama bagi setiap karyawan untuk memperoleh penghargaan dan mendapatkan promosi jabatan sesuai dengan kinerjanya.

2. Melakukan tindakan yang menguntungkan bagi karyawan terutama bagi karyawan yang berprestasi mengusahakan seperti perbaikan kesejahteraan karyawan sehingga karyawan dapat memenuhi kewajibannya sesuai dengan tugas pekerjaannya untuk kemajuan perusahaan.

3. Mempunyai ketentuan yang mengatur tentang status pekerja. Setiap karyawan sudah dianggap sebagai karyawan tetap dan berhak memperoleh upah ditambah beberapa tunjangn, apabila karyawan telah bekerja selama enam bulan sebagai masa percobaan.

Walaupun demikian masih dijumpai beberapa karyawan yang kurang puas terhadap kebijakan hubungan industrial yang telah dilakukan Hotel Fave Petitenget 
Kabupaten Badung seperti adanya ketidaksesuaian antara harapan karyawan dengan penghargaan finansial yang diterima atas prestasi kerjanya, hal ini menyebabkan masalah pribadi bagi karyawan terhadap manajemen perusahaan terutama jika dikaitkan dengan prestasinya dalam menyelesaikan beban kerja berlebihan. Dan juga kurangnya interaksi antara manajemen dengan karyawan, hal ini dapat dilihat dari sering ada tugas mendadak bagi karyawan yang beban kerja yang berat tanpa pemberitahuan sebelumnya dari manajemen, sehingga karyawan merasa tidak siap secara fisik maupun mental dan sering melakukan komplain.

\section{Komunikasi $\left(\mathbf{X}_{1}\right)$}

(Diah Ayu, 2012) :

1. Peran komunikasi

2. Komunikasi dalam kelompok

3. Manipulasi dalam penyampaian informasi

4. Menggunakan bahasa yang baik

5. Komunikasi membantu meningkatkan motivasi

6. Komunikasi memberikan informasi

7. Komunikasi dilakukan secara efektif

8. Kebenaran informasi

\section{Hubungan Industrial ( $\left.\mathbf{X}_{2}\right)$}

(Diah Sinta Dewi, 2015) :

1. Langkan menyelesaikan pertikaian

2. Menempatkan diri

3. Langkah efektif serikat pekerja

4. Hubungan yang saling mendukung

5. Hubungan akomodatif

6. Hubungan yang saling menghormati

7. Kerja sama

8. Hubungan yang saling menghargai
Gambar 1.

Kerangka Berfikir Pengaruh Komunikasi dan Hubungan Industrial Terhadap Kepuasan Kerja Karyawan Pada Hotel Fave Petitenget Kabupaten Badung 
Perumusan Hipotesis

1. Apakah ada pengaruh yang positif dan signifikan Komunikasi terhadap Kepuasan Kerja Karyawan pada Hotel Fave Petitenget Kabupaten Badung.

2. Apakah ada pengaruh yang positif dan signifikanHubungan industrial

\section{Operasional Variabel Penelitian}

\section{Identifikasi Variabel}

a. Variabel bebas adalah variabel yang menjadi penyebab timbulnya variabel lain atau mempengaruhi variabel yang lain. Dalam penelitian ini yang menjadi variabel bebas yaitu komunikasi dan hubungan industrial.

b. Variabel terikat adalah variabel yang menjadi akibat dari variabel bebas. Dalam penelitian ini yang menjadi variabel terikat yaitu kepuasan kerja karyawan.

\section{Definisi Operasional Variabel}

Komunikasi (X1) adalah sebuah proses dua arah dalam penyampaian informasi atau pesan-pesan oleh seseorang kepada orang lain dengan tujuan dpata saling mengerti dan memahami. Arti komunikasi demikian penting dalam meneruskan informasi kepada orang lain sehingga dapat diterima dan dipahami.

Hubungan industrial (X2) adalah hubungan formal antara pengusaha, pekerja dan pemerintah menyangkut terhadap kepuasan kerja karyawan pada Hotel Fave Petitenget Kabupaten Badung.

3. Apakah ada pengaruh yang positif dan signifikanantara Komunikasi dan Hubungan Industrial terhadap Kepuasan Kerja Karyawan pada Hotel Fave Petitenget Kabupaten Badung

seluruh aspek dan permasalahan ekonomi, sosial, politik dan budaya yang didasarkan atas kerjasama yang menguntungkan.

Kepuasan kerja (Y) adalah sikap emosional yang menyenangkan dan mencintai pekerjaannya.Sikap ini dicerminkan oleh moral kerja, kedisiplinan dan prestasi kerja.

\section{Populasi dan Sampel}

\section{Populasi}

Populasi adalah wilayah generalisasi yang terdiri atas obyek/subyek yang mempunyai kualitas dan karakteristik tertentu yang ditetapkan oleh peneliti untuk dipelajari dan kemudian ditarik kesimpulannya (Sugiyono, 2017 : 119). Dalam penelitian ini yang menjadi populasinya adalah seluruh karyawan Hotel Eden di Kuta yang berjumlah 78 orang.

\section{Sampel}

Melihat jumlah populasi hanya sebesar 78 orang, maka layak untuk diambil semua untuk dijadikan sebagai sampel sehingga penelitian ini merupakan penelitian sensus. Pengambilan sampel yang digunakan adalah metode sensus, hal itu karena ditinjau dari 
wilayahnya penelitian ini hanya meliputi daerah atau subyek yang sangat sempit (Arikunto, 2016 : 115). Sehingga peneliti merasa

\section{METODE PENGUMPULAN DATA}

1. Penelitian lapangan (field research), yaitu penelitian yang dilakukan secara langsung terhadap objek penelitian. Teknik yang digunakan adalah :

a. Metode pengamatan (observasi) : yaitu suatu cara pengumpulan data penelitian yang akurat dengan pengamatan secara langsung ke objek penelitian, dalam hal ini adalah Hotel Fave Petitenget Kabupaten Badung.

b. Wawancara (interview) : yaitu teknik pengumpulan data dengan mengadakan tanya jawab langsung dengan pihak yang terkait, baik pimpinan dan karyawan mengenai masalah yang terkait dengan penelitian ini.

c. Angket (Qestionnaire) : yaitu pengumpulan data melalui daftar pertanyaan untuk seterusnya diisi oleh responden sesuai pendapatnya masingmasing.

2. Studi kepustakaan, yaitu pengumpulan data melalui literatur-literatur yang terkait dengan masalah-masalah yang diteliti untuk mendapatkan bahan-bahan yang akan perlu untuk meneliti secara keseluruhan tanpa harus mengambil sampel dalam jumlah tertentu.

dijadikan landasan teoritis dalam penyusunan skripsi ini.

3. Dokumentasi, yaitu cara pengumpulan data dari pencatatan dokumen yang sudah ada, seperti jumlah karyawan dan data-data lain yang diperlukan dalam penelitian ini.

4. Sumber data, yaitu data-data yang diperoleh dalam penelitian melalui :

a. Data primer, adalah data yang diperoleh dari pihak yang diminta keterangan seperti hasil wawancara dan hasil pengisian kuesioner yang diajukan oleh peneliti.

b. Data sekunder, adalah data primer yang telah diolah lebih lanjut dan disajikan dalam bentuk tabel-tabel atau diagram-diagram.

5. Jenis data, yaitu pengumpulan data-data yang diambil dalam penelitian dengan menggunakan :

a. Data kualitatif, adalah data yang tidak berupa angkaangka dan kebenarannya tidak dapat dihitung, seperti gambaran umum perusahaan, struktur organisasi.

b. Data kuantitatif, adalah data yang berupa angka-angka dan dapat dihitung, seperti jumlah karyawan, 
skor/bobot dari kuesioner efektivitas komunikasi, hubungan industrial dan kepuasan kerja karyawan.

\section{A. Teknik Analisis Data}

Analisis yang dipergunakan untuk mengetahui pengaruh signifikan komunikasi dan hubungan industrial terhadap kepuasan kerja karyawan pada Hotel Fave Petitenget Kabupaten Badung adalah :

data yang bersifat kualitatif ke dalam bentuk kuantitatif dalam penelitian ini menggunakan skala likert. Skala likert digunakan untuk mengukur sikap, pendapat dan persepsi seseorang atau kelompok tentang kejadian atau gejala sosial (Sugiyono, 2017 : 21). Tingkat skala likert yang digunakan dalam penelitian ini adalah :

Tabel 2

Alternatif Jawaban Responden

\begin{tabular}{|l|c|}
\hline \multicolumn{1}{|c|}{ Alternatif Jawaban } & Nilai Items/Skor \\
\hline Sangat Baik & 5 \\
\hline Baik & 4 \\
\hline Kurang Baik & 3 \\
\hline Tidak Baik & 2 \\
\hline Sangat Tidak Baik & 1 \\
\hline
\end{tabular}

Sumber : Sugiyonon $(2017: 21)$

\section{Analisis kuantitatif}

Analisis kuantitatif digunakan sebagai alat bantu statistik untuk menjawab hipotesis yang telah diajukan yang berupa angka-angka yang berkaitan dengan penelitian yaitu pengaruh komunikasi $\left(\mathrm{X}_{1}\right)$ dan hubungan industrial $\left(\mathrm{X}_{2}\right)$ terhadap kepuasan kerja karyawan (Y) pada Hotel Fave Petitenget Kabupaten Badung. Analisis kuantitatif dalam penelitian ini meliputi uji validitas dan reliabilitas, analisis regresi linier berganda, uji asumsi klasik, uji statistik $\mathrm{f}$, uji statistik $\mathrm{t}$, analisis korelasi berganda dan analisis determinasi $\left(\mathrm{R}^{2}\right)$.

\section{Analisis kualitatif}

Analisis kualitatif yaitu suatu analisis deskriptif yang mendasarkan pada perhitungan jawaban responden dengan mengelompokkan data kedalam tabel-tabel perhitungan serta dinyatakan dalam persentase untuk melihat penilaian responden terhadap variabel yang diteliti.Skala pengukuran untuk mengubah 
valid, sehingga harus dibuang atau diganti dengan pertanyaan atau pernyataan yang lain. Ketentuan suatu instrumen dikatakan valid atau Instrumen yang reliable adalah instrumen yang bila digunakan beberapa kali untuk mengukur obyek yang sama, akan menghasilkan data yang sama. Digunakannya instrumen yang reliable dalam pengumpulan data, diharapkan hasil penelitian akan

b. Analisis Regresi Linier

c. Berganda

Analisis ini dimaksudkan untuk mengetahui ada tidaknya pengaruh dari dua variabel atau lebih secara bersama-sama terhadap variabel dependen (Sugiyono, 2017 : 170). Selain itu dapat pula diketahui besarnya sumbangan pengaruh dari variabel bebas yaitu komunikasi dan hubungan industrial secara bersamasama terhadap variabel dependen yaitu, kepuasan kerja karyawan pada Hotel Fave Petitenget Kabupaten Badung.

d. Pengujian Hipotesis Regresi

1) Uji Koefisien Regresi Secara Simultan (F-test)

Uji $F$ dilakukan untuk mengetahui pengaruh antara variabel independen terhadap variabel dependen secara bersamasama yaitu dengan langkahlangkah sebagai berikut :

a) Merumuskan hipotesis

Ho : bi $=0$,

tinya tidak terdapat pengaruh yang signifikan antara variabel bebas secara simultan terhadap variabel terikat. sah apabila memiliki koefisien korelasi Pearson Product Moment (r) > 0,3 dengan alpha sebesar 0,05 (Sugiyono, 2017 : 172).

menjadi reliable juga. Instrumen yang reliable merupakan syarat mutlak mendapatkan hasil penelitian reliable. Suatu instrumen dikatakan reliable atau handal, apabila memiliki koefisien alpha $(\alpha)$ lebih besar dari 0,60 (Sugiyono, 2017 : 172).

Persamaan garis regresi linier berganda yang dimaksud adalah sebagai berikut :

$\mathrm{Y}=\mathrm{a}+\mathrm{b}_{1} \mathrm{X}_{1}+\mathrm{b}_{2} \mathrm{X}_{2}$

Dimana:

$\mathrm{Y}=$ Kepuasan kerja karyawan

$\mathrm{a} \quad=$ Nilai konstanta

$\mathrm{X}_{1} \quad=$ Komunikasi

$\mathrm{X}_{2}=$ Hubungan industrial

$\mathrm{b}_{1} \quad=$ Koefisien regresi dari $\mathrm{X}_{1}$

$\mathrm{b}_{2} \quad=$ Koefisien regresi dari $\mathrm{X}_{2}$

Ho $\quad$ : $\quad$ bi $\quad \neq \quad$, tinya terdapat pengaruh ar tinya terdapat pengaruh yang signifikan antara variabel bebas secara simultan terhadap variabel terikat.

b) Menentukan taraf nyata (level of significant $(\alpha)$ )

Menentukan taraf signifikan $(\alpha)=$ 5\% dengan derajat kebebasan (df) $=(\mathrm{k}-1) ;(\mathrm{n}-\mathrm{k})$. dengan demikian Ftabel adalah $\mathrm{F} \alpha_{(\mathrm{k}-1) ;(\mathrm{n}-\mathrm{k})}$

c) Kriteria pengujian

Ho diterima jika F-hitung $\leq$ F-tabel atau signifikansi $\geq \alpha(0,05)$ 
Ho ditolak jika F-hitung > F-tabel atau signifikansi $<\alpha(0,05)$

d) Kesimpulan

Jika Ho diterima, berarti semua variabel bebas yang terdiri dari komunikasi dan hubungan industrial secara simultan tidak

2) Uji Koefisien Regresi Secara Parsial (t-test)

a) Merumuskan hipotesis

Ho : bi $\quad=\quad 0$, ar tinya tidak terdapat pengaruh yang signifikan antara variabel bebas secara parsial terhadap variabel terikat.

Ho : bi $\neq 0$, tinya terdapat pengaruh yang signifikan antara variabel bebas secara parsial terhadap variabel terikat.

b) Menentukan taraf nyata (level of significant $(\alpha)$ )

Menentukan taraf nyata $(\alpha)=5 \%$ atau 0,05 dan $(d f)=(n-k)$. Dengan demikian $\mathrm{t}$-tabel adalah $\mathrm{t}_{\mathrm{a} / 2}(\mathrm{n}-\mathrm{k})$, dimana $\mathrm{n}$ adalah besarnya sampel dan $\mathrm{k}$ adalah banyaknya variabel. berpengaruh signifikan terhadap variabel terikat yaitu kepuasan kerja karyawan.Sebaliknya bila Ho ditolak berarti variabel bebas tersebut secara simultan berpengaruh signifikan terhadap variabel terikat.

c) Kriteria pengujian

Ho diterima jika -t-hitung $\leq \mathrm{t}$ hitung $\leq$ t-tabel atau jika signifikansi $>0,05$

Ho ditolak jika t-hitung > t-tabel atau t-hitung < -t-tabel atau jika signifikansi $<0,05$

d) Kesimpulan

Ho diterima jika t-hitung berada diantara -t-tabel dan t-tabel

Ho ditolak jika t-hitung < -t-tabel atau t-hitung $>$ t-tabel

e. Analisis Korelasi Berganda

Analisis ini digunakan untuk mengetahui kuat lemahnya atau tinggi rendahnya hubungan antara komunikasi dan hubungan industrial terhadap kepuasan kerja karyawan pada Hotel Fave Petitenget Kabupaten Badung, dengan bantuan komputer program SPSS 24

Tabel 3.

Pedoman untuk Memberikan Interpretasi Koefisien Korelasi

\begin{tabular}{|c|c|}
\hline Interval Koefisien & Tingkat Hubungan \\
\hline $0,00-0,199$ & Sangat Rendah \\
$0,20-0,399$ & Rendah \\
$0,40-0,599$ & Sedang \\
$0,60-0,799$ & Kuat \\
$0,80-1,000$ & Sangat Kuat \\
\hline
\end{tabular}

Sumber : Sugiyono $(2017: 214)$ 
f. Analisis Determinasi

lisis ini bertujuan untuk mengetahui atau menentukan seberapa besar pengaruh kepemimpinan dan lingkungan kerja fisik terhadap kinerja karyawan yang dinyatakan dalam presentase. Dalam penelitian ini dengan menggunakan bantuan komputer program SPSS 24 nilai determinasi dapat dilihat melalui nilai $\mathrm{R}$ square dan dinyatakan dalam presentase

\section{Pembahasan Hasil Penelitian}

Dalam bab ini akan

dijelaskan mengenai hasil dari penelitian yang telah dilakukan dan diolah untuk mengetahui pengaruh komunikasi dan hubungan industrial terhadap kepuasan kerja karyawan pada Hotel Fave Petitenget Kabupaten Badung.

\section{Hasil Analisis Kualitatif}

\subsection{Deskripsi Data Penelitian}

Berdasarkan hasil tabulasi data yang diperoleh melalui kuesioner yang telah disebarkan kepada 78 orang responden yang merupakan karyawan Hotel Fave Petitenget Kabupaten Badung, data penelitian untuk variabel komunikasi $\left(\mathrm{X}_{1}\right)$, hubungan industrial $\left(\mathrm{X}_{2}\right)$ dan kepuasan kerja karyawan (Y)

1.2 Deskripsi Data Penelitian Tabel 4.

Karakteristik Responden Berdasarkan Jenis Kelamin

\begin{tabular}{|l|l|l|l|}
\hline $\mathbf{N}$ & $\begin{array}{l}\text { Jenis } \\
\text { Kelamin }\end{array}$ & $\begin{array}{l}\text { Juml } \\
\text { ah }\end{array}$ & $\begin{array}{l}\text { Persent } \\
\text { ase }\end{array}$ \\
\hline $\mathbf{1}$ & $\begin{array}{l}\text { Laki } \\
\text { laki }\end{array}$ & $\mathbf{4 0}$ & $\mathbf{5 1 \%}$ \\
\hline $\mathbf{2}$ & $\begin{array}{l}\text { Perempu } \\
\text { an }\end{array}$ & $\mathbf{3 8}$ & $\mathbf{4 9 \%}$ \\
\hline & Jumlah & $\mathbf{7 8}$ & $\mathbf{1 0 0 \%}$ \\
\hline
\end{tabular}

diolah, 2018

Sumber : data primer

Pada Tabel 4. dapat dilihat jumlah responden laki - laki sebanyak 40 orang dengan presentase sebesar $51 \%$ dan perempuan sebanyak 38 orang dengan presentase sebesar $49 \%$.

Pada Tabel 5 dapat dideskripsikan bahwa responden yang berusia dibawah 20 tahun berjumlah 10 orang (19\%), pada usia 20 - 30 tahun jumlah responden berjumlah 17 orang (21\%), pada usia $30-40$ tahun berjumlah 30 orang (38\%), dan responden yang berusia diatas 40 tahun berjumlah 5 orang (9\%).

\begin{tabular}{|c|c|}
\hline Dari & Jumlah \\
\hline esponden & Berdasarkan \\
\hline ndidikan & adalah SLTA sebanyak \\
\hline orang & Pendidikan \\
\hline Diploman II] & I seabnayak 23 orang (29 \\
\hline Str & a 1 sebanyak 38 \\
\hline
\end{tabular}
$(49 \%)$. 
Tabel 5

Karakteristik Responden Berdasarkan Usia

\begin{tabular}{|l|l|l|l|}
\hline No & Usia (Tahun) & Jumlah & Persentase \\
\hline 1 & $15-20$ & 10 & $19 \%$ \\
\hline 2 & $21-30$ & 17 & $21 \%$ \\
\hline 3 & $31-40$ & 20 & $22 \%$ \\
\hline 4 & $>40$ & 30 & $38 \%$ \\
\hline & Jumlah & 78 & $100 \%$ \\
\hline
\end{tabular}

Sumber : data primer diolah, 2018

Tabel 6

Karakteristik Responden Berdasarkan Pendidikan

\begin{tabular}{|l|l|l|l|}
\hline No & Pekerjaan & Jumlah & Persentase \\
\hline 1 & SLTA & 17 & $22 \%$ \\
\hline 2 & D III & 23 & $29 \%$ \\
\hline 3 & SI. & 38 & $49 \%$ \\
\hline & Jumlah & 78 & $100 \%$ \\
\hline
\end{tabular}

Sumber : data primer diolah, 2018

\section{Idenfikasi Varibel}

Berdasarkan hasil tabulasi data yang diperoleh melalui kuesioner yang telah disebarkan kepada 78 orang responden yang merupakan karyawan Hotel Fave Petitenget Kabupaten Badung, dengantiga variabel penelitian:

1 Variabel komunikasi $\left(\mathrm{X}_{1}\right)$,

2. Variabel hubungan industrial $\left(\mathrm{X}_{2}\right)$ dan

3. Variabel kepuasan kerja karyawan (Y)

.Ketiga variabel tersebut menggambarkan tujuan dari suatu perusahaan untuk digabungkan dalam kesempatan komunikasi, hubungan industrial guna menumbuhkan kepuasan kerja karyawan serta tingkat responsif perusahaan terhadap kepuasan kerja karyawan . Komunikasi dan hubungan industrial menjadi pusat perhatian manajemen dalam membangun strategi meningkatkan kepuasan kerja karyawan, membangun keunggulan bersaing, mengembangkan inovasi, mengidentifitasi kebutuhan dan keinginan karyawan dan memonitor kinerja, melalui orientasi kepuasan kerja karyawan 
Dari

$$
\text { hasil }
$$

Item-Total

StatisticsCronbach's Alpha moment Pearson, diketahui bahwa semua item pertanyaan adalah valid. Penelitian Variabel independen pada penelitian ini adalah Komunikasi (X1),Hubungan industrial (X2), Kepuasan kerja karyawan (Y). Selanjutnya koefisien korelasi yang diperoleh $r$ masih harus diuji signifikansinya dengan pertanyaan pada kuesioner sehingga dapat dikatakan semua item

membandingkan dengan tabel r. Butir pertanyaan dikatakan valid jika nilai $r$ hitung $>\mathrm{r}$ tabel atau nilai $\mathrm{p}<0,05$ dengan uji validitas adalah suatu dapat dipercaya kebenarannya sesuai dengan kenyataan. Menurut Sugiyono (2010:172) sesuai tabel 7 dibawah

Tabel.7

Sumber: Data primer 2018

\section{Hasil Uji Validitas Variabel}

\begin{tabular}{|c|c|c|c|c|}
\hline Variabel & $\begin{array}{c}\text { Nomer } \\
\text { Item }\end{array}$ & Rhitung & Rtable & Keterangan \\
\hline Komunikasi & 1. & .943 & 0,312 & Valid \\
$(\mathrm{X})$ & 2 & .942 & 0,312 & Valid \\
& 3 & .944 & 0,312 & Valid \\
& 4 & .943 & 0,312 & Valid \\
& 5 & .943 & 0,312 & Valid \\
& 6 & .944 & 0,312 & Valid \\
& 7 & .941 & 0,312 & Valid \\
Hubungan & 1. & .944 & 0,312 & Valid \\
Industrial & 2 & .945 & 0,312 & Valid \\
(X) & 3 & .942 & 0,312 & Valid \\
& 4 & .944 & 0,312 & Valid \\
& 5 & .942 & 0,312 & Valid \\
& 6 & .943 & 0,312 & Valid \\
& 7 & .942 & 0,312 & Valid \\
& 8 & .945 & 0,312 & Valid \\
Kepuasan & 1 & .943 & 0,312 & Valid \\
Kinerja & 2 & .942 & 0,312 & Valid \\
Karyawan & 3 & .944 & 0,312 & Valid \\
(Y) & 4 & .942 & 0,312 & Valid \\
& 5 & .943 & 0,312 & Valid \\
& 6 & .943 & 0,312 & Valid \\
& 7 & .942 & 0,312 & Valid \\
& 8 & .943 & 0,312 & Valid \\
& .944 & 0,312 & Valid \\
\hline
\end{tabular}


Sesuai hasil.kerja yang dapat dicapai oleh seseorang atau kelompok orang dalam organisasi, sesuai dengan wewenang dan tanggung jawab masing-masing dalam rangka mencapai tujuan (Ardiana, 2007). Kinerja, adalah hasil kerja yang dapat dicapai oleh seseorang atau kelompok orang dalam organisasi dan

Tabel 8

\section{Hasil Uji Reliability Statistics}

\begin{tabular}{|c|c|c|}
\hline & \multicolumn{2}{|l|}{ Reliability Statistics } \\
\hline Variabel & Cronbach's Alpha & Reabel \\
\hline & .945 & 24 \\
\hline Komunikasi (X) & & Reliabel \\
\hline Hubungan Industrial (X2) & & Reliabel \\
\hline Kepuasan Kerja Karyawan (Y) & & Reliabel \\
\hline
\end{tabular}

Sumber: Data primer 2018

Dari tabel 8 diatas hasil uji reability di atas maka dapat diketahui bahwa dari masing - masing variabel memiliki nilai $r$ alpha hitung (cronbach's Alpha) sebesar 0,945 lebih besar dari pada nilai $\mathrm{r}$ alpha tabel 0,6 Dengan demikian, hasil uji reliabilitas semua variabel adalah reliabl

\section{HASIL PENELITIAN DAN PEMBAHASAN}

Berdasarkan Latar belakang, Landasan Teori dan kerangka pemikiran dan kerangka konsep serta metode penelitian dapat dianalysis data-data untuk menjawab hipotesis terhadap pengaruh secara parsial masing - masing merupakan sarana penentu dalam suatu proses untuk mencapai tujuan organisasi. Kinerja organisasi harus dapat diukur berdasarkan ukuran tertentu dan dalam kesatuan waktu. Indikator komunikasi, hubungan industrial dan kepusan kerja karyawan 
Tabel 9

Hasil Analisis Korelasi

\begin{tabular}{|c|c|c|c|c|}
\hline \multicolumn{5}{|c|}{ Correlations } \\
\hline & & $\begin{array}{l}\text { Komunikasi } \\
\text { (X) }\end{array}$ & $\begin{array}{l}\text { Hubungan } \\
\text { Industrial } \\
\text { (X2) }\end{array}$ & $\begin{array}{l}\text { Kepuasan } \\
\text { Kerja } \\
\text { Karyawan } \\
(\mathrm{Y})\end{array}$ \\
\hline \multirow{3}{*}{$\begin{array}{l}\text { Komunikasi } \\
\text { (X) }\end{array}$} & Pearson Correlation & 1 & $.789^{* *}$ & $.765^{* *}$ \\
\hline & Sig. (2-tailed) & & .000 & .000 \\
\hline & $\mathrm{N}$ & 78 & 78 & 78 \\
\hline \multirow{3}{*}{$\begin{array}{l}\text { Hubungan } \\
\text { Industrial } \\
\text { (X2) }\end{array}$} & Pearson Correlation & $.789^{* *}$ & 1 & $.812^{* *}$ \\
\hline & Sig. (2-tailed) & .000 & & .000 \\
\hline & $\mathrm{N}$ & 78 & 78 & 78 \\
\hline \multirow{3}{*}{$\begin{array}{l}\text { Kepuasan } \\
\text { Kerja } \\
\text { Karyawan } \\
\text { (Y) }\end{array}$} & Pearson Correlation & $.765^{* *}$ & $.812^{* *}$ & 1 \\
\hline & Sig. (2-tailed) & .000 & .000 & \\
\hline & $\mathrm{N}$ & 78 & 78 & 78 \\
\hline
\end{tabular}

Berdasarkan tabel 10 di bawah ini hasil perhitungan statistik menunjukkan nilai $\mathrm{F}$ hitung $=87.48>\mathrm{F}$ table $(2.02)=85.46$ dan signifikansi sebesar $0,000<0,05$. Maka model regresi dapat digunaka untuk memprediksi kepuasan kerja karyawan

\section{Tabel 10}

Uji F

Hasil Analisis Anova

\begin{tabular}{|l|l|r|r|r|r|r|}
\hline \multicolumn{7}{|c|}{ ANOVA $^{\mathrm{a}}$} \\
\hline \multirow{3}{*}{\begin{tabular}{l} 
Model \\
\multirow{2}{*}{1}
\end{tabular}} & $\begin{array}{c}\text { Sum of } \\
\text { Squares }\end{array}$ & Df & Mean Square & F & \multicolumn{1}{c|}{ Sig. } \\
\cline { 2 - 8 } & Regression & 1018.335 & 2 & 509.168 & 87.486 & $.000^{\mathrm{b}}$ \\
\cline { 2 - 8 } & Residual & 436.498 & 75 & 5.820 & & \\
\cline { 2 - 8 } & Total & 1454.833 & 77 & & & \\
\hline
\end{tabular}

a. Dependent Variable: Kepuaan Kerja Karyawan (Y)

b. Predictors: (Constant), Hubungan Industrial (X2), Komunikasi (X) 
Berdasarkan Tabel 11 di bawah dapat disimpulkan bahwa variabel Kepuasan Kerja karyawan (Y) dipengaruhi oleh variabel yang digunakan dalam penelitian yaitu Komunikasi (X1), dan Hubungan Industrial (X2) sehingga terbentuk persamaan seperti berikut ini: $\mathrm{Y}=\mathrm{a}+$ b1 $\mathrm{X} 1+\mathrm{b} 2 \mathrm{X} 2=\mathrm{Y}=2.905+$ $0.341+0.560$

Dari persamaan regresi berganda tersebut dijelaskan sebagai berikut: (Konstanta) a= 2.905 ; artinya apabila variabel Komunikasi (X1), dan Variabel Hubungan Industrial (X2) diasumsikan tidak memiliki pengaruh sama sekali $(=0)$ maka kepuasan kerja karyawan adalah sebesar 2.904 maka Variabel Komunikasi (X1) dengan memiliki koefisien sebesar 0,341 dan variabel hubungan industrial memiliki koefisien sebesar 0,560

Tabel 11

Hasil Analisis Persamaan Regresi Linier Berganda

\begin{tabular}{|c|c|c|c|c|c|c|}
\hline \multicolumn{7}{|c|}{ Coefficients $^{\mathbf{a}}$} \\
\hline & & \multicolumn{2}{|c|}{$\begin{array}{l}\text { Unstandardized } \\
\text { Coefficients }\end{array}$} & \multirow{2}{*}{$\begin{array}{c}\begin{array}{c}\text { Standardized } \\
\text { Coefficients }\end{array} \\
\text { Beta }\end{array}$} & \multirow[b]{2}{*}{$\mathrm{T}$} & \multirow[b]{2}{*}{ Sig. } \\
\hline \multicolumn{2}{|c|}{ Model } & $\mathrm{B}$ & Std. Error & & & \\
\hline \multirow[t]{3}{*}{1} & (Constant) & 2.905 & 2.109 & & 1.377 & .173 \\
\hline & $\begin{array}{l}\text { Komunikasi } \\
\text { (X) }\end{array}$ & .341 & .106 & .330 & 3.202 & .002 \\
\hline & $\begin{array}{l}\text { Hubungan } \\
\text { Industrial } \\
\text { (X2) }\end{array}$ & .560 & .105 & .551 & 5.349 & .000 \\
\hline
\end{tabular}

Berdasarkan Tabel 12 dibawah dapat diketahui masing-masing variabel independent memiliki tingkat signifikansi kurang dari 0,05. Hal ini berarti bahwa masing-masing variabel independent berpengaruh signifikan terhadap variabel dependent. Berikut ini dijelaskan hasil perhitungan uji t pada masingmasing variablel:

Variabel Komunikasi

1. Hasil uji $t$ pada variabel Komunikasi menghasilkan: $t$ hitung sebesar 3.202 dan signifikansi sebesar 0,002. $\mathrm{t}$ hitung 3.202> $t$ tabel yang nilainya 1,663 dengan tingkat signifikansi $0,173>0,05$, maka dapat diketahui bahwa hipotesis yang menyatakan Komunikasi berpengaruh positif signifikan terhadap kepuasan kerja karyawan.

2. Variabel Hubungan Industrial menghasil $t$ hitung sebesar 5.349dan signifikansi sebesar 0,000. $\mathrm{t}$ hitung 5.349> t tabel yang nilainya 1,663 dengan tingkat 
signifikansi $0,173>0,05$, maka dapat diketahui bahwa hipotesis yang menyatakan hubungan industrial berpengaruh positif signifikan terhadap kepuasan kerja karyawan.
3. Hipotesi diterima dengan t hitung 1.377> $t$ tabel0,663, maka hipotesis yang menyatakan adanya pengaruh yang positif signifikan antara Komunikasidan hubungan industrial dengan Kepuasan kerja karywan

Tabel 12

Koefisien

\begin{tabular}{|c|c|c|c|c|c|c|}
\hline \multicolumn{7}{|c|}{ Coefficients $^{\mathbf{a}}$} \\
\hline & & \multicolumn{2}{|c|}{ Unstandardized efficients } & $\begin{array}{l}\text { Standardized } \\
\text { Coefficients }\end{array}$ & \multirow[b]{2}{*}{$\mathrm{T}$} & \multirow[b]{2}{*}{ Sig. } \\
\hline \multicolumn{2}{|c|}{ Model } & $\mathrm{B}$ & Std. Error & Beta & & \\
\hline \multirow[t]{3}{*}{1} & (Constant) & 2.905 & 2.109 & & 1.377 & .173 \\
\hline & $\begin{array}{c}\text { Komunika } \\
\text { si } \\
(\mathrm{X})\end{array}$ & .341 & .106 & .330 & 3.202 & .002 \\
\hline & $\begin{array}{c}\text { Hubungan } \\
\text { Industrial } \\
\text { (X2) }\end{array}$ & .560 & .105 & .551 & 5.349 & .000 \\
\hline
\end{tabular}

Berdasarkan Tabel 13 diawah dapat diketahui bahwa koefisien determinasi (adjusted R ) yang diperoleh sebesar 69,2\% Hal ini menunjukkan bahwa Komunkasi dan hubungan industrial terhadap kepuasan kerja karyawan sebesar $69,1 \%$ Sedangkan sisanya sebesar $30,9 \%$ komunikasi dan hubungan industrial dipengaruhi oleh variabelvariabel lainnya yang tidak diteliti dalam penelitian ini. 
Jurnal Satyagraha, Vol. 01, No. 02, Agustus 2018 - Januari 2019 ISSN : 2620-6358

\section{Tabel 13}

\section{Hasil Analisis Determinasi}

\begin{tabular}{|c|c|c|c|c|}
\hline \multicolumn{5}{|c|}{ Model Summary } \\
\hline Model & $\mathrm{R}$ & R Square & Adjusted R Square & $\begin{array}{l}\text { Std. Error of the } \\
\text { Estimate }\end{array}$ \\
\hline 1 & $.837^{\mathrm{a}}$ & .700 & .692 & 2.412 \\
\hline
\end{tabular}

\section{PEMBAHASAN}

Pada hasil penelitian, analisis dan pembahasan mengenai masalah hubungan antara variabel independent dan dependent dapat dijelaskan sebagai berikut:

1. Variabel Komunikasi (X1) secara parsial berpengaruh signifikan terhadap variabel Kepuasan kerja karyawan (Y). Dengan uji $t$ pada variabel Komunikasi menghasilkan: t hitung sebesar 3.202 dan signifikansi sebesar 0,002 . thitung 3.202 $>\mathrm{t}$ tabel yang nilainya 1,663 dengan tingkat signifikansi $0,173>0,05$, maka dapat diketahui bahwa hipotesis yang menyatakan Komunikasi berpengaruh positif signifikan terhadap kepuasan kerja karyawan. Sehinga komunikasi mengambil peran yang doniman dalam kepuasan kerja karyawan

2. Variabel Hubungan Industrial (X2) secara parsial signifikan menghasil $\mathrm{t}$ hitung sebesar 5.349 dan signifikansi sebesar 0,000. $\mathrm{t}$ hitung $5.349>\mathrm{t}$ tabel yang nilainya 1,663 dengan tingkat signifikansi $0,173>0,05$, maka dapat diketahui bahwa hipotesis yang menyatakan hubungan industrial berpengaruh positif signifikan terhadap kepuasan kerja karyawan, hal ini membuktikan hubungan industrial berjalan harmonis.

3. Hipotesi diterima dengan $t$ hitung $1.377>$ t tabel 0,663, maka hipotesis yang menyatakan adanya pengaruh yang positif signifikan antara Komunikasi dan hubungan industrial dengan Kepuasan kerja karywan. Dengan baiknya hubungan ke dua variabel sehingga kepuasan kerja karyawan dapat berjalan dengan baik

4. Bahwa koefisien determinasi (adjusted $\mathrm{R}$ ) yang diperoleh sebesar $69,2 \%$ Hal ini menunjukkan bahwa kepuasan kerja karyawan di pengaruhi Komunkasi dan hubungan industrial sebesar $69,1 \%$ Sedangkan sisanya sebesar $30,9 \%$ kepuasan kerja karyawan, komunikasi dan 
Jurnal Satyagraha, Vol. 01, No. 02, Agustus 2018 - Januari 2019 ISSN : 2620-6358

hubungan industrial dipengaruhi oleh variabel-variabel lainnya yang tidak diteliti dalam penelitian ini.

Pada hasil penelitian, analisis dan pembahasan mengenai masalah hubungan antara Komunikasi, Hubungan Industrial dan Kepuasan kerja Karyawan dapat diambil kesimpulan.

\section{KESIMPULAN DAN SARAN}

1. Komunikasi secara parsial berpengaruh signifikan terhadap Kepuasan kerja karyawan . Sehinga komunikasi mengambil peran yang doniman dalam kepuasan kerja karyawan Maka komunikasi yang baik dapat meningkatkan kepuasan kerja karyawan pada Hotel Fave Petitenget Kabupaten Badung.

2. .Hubungan Industrial berpengaruh secara parsial signifikan terhadap kepuasan kerja karyawan, hal ini membuktikan hubungan industrial berjalan harmonis.Dalam tingkat hubungan industrial pada hote five Petitenget kabupaten badung sesuai dengan ketentuan yabg berlaku

Pengaruh antara komunikasi dan hubunan industrial yang positif signifikan terhadap Kepuasan kerja karywan.hal ini menunjukan baiknya hubungan ke dua variabel sehingga kepuasan kerja karyawan dapat berjalan dengan baik sehingga karyawan merasa nyaman dalam bekerja pada hotel five petitenget kabupaten badung.

Saran-saran
Berdasarkan hasil kesimpulan yang telah diuraikan diatas, maka penulis ingin menyampaikan saran yang bisa dijadikan bahan pertimbangan untuk mengambil suatu kebijakan atau keputusan yang terkait dengan pengaruh komunikasi dan hubungan industrial terhadap kepuasan kerja karyawan pada Hotel Fave Petitenget Kabupaten Badung. Adapun saran yang ingin disampaikan yaitu :

1. Walaupun komunikasi bejalan baik pada hotel five petitenget kabupaten badung perlu meningkatkan kewaspadaan dalam komunikasi baik pihak internal dan ekternal guna menghindari hal yang tidak di ingikan dengan adanya komunikasi global.

2. Hubungan industrial yang berjalan baik selama ini perlu

3. adanya pengembangan struktrur organisai untuk menikatakan karier karyawan.

4. Penelitian lebih lanjut di harapakan peneliti pada variabel-variabel lain.

\section{DAFTAR PUSTAKA}

Jurnal EMBA; Ch. Katiandagho,, S.L. Mandey., L. Mananeke (2014, Vol.2 No.3 Hal. 1592-1602) Pengaruh Disiplin Kerja Kepemimpinan Dan Motivasi Terhadap Kinerja Pegawai

eJournal Ilmu Administrasi Bisnis; Febrisma Ramadhiya Findarti1 (2016, 4 : 937946 - ISSN 2355-5408) Pengaruh Pengembangan Sumber Daya Manusia Terhadap Kinerja Pegawai 
Jurnal Satyagraha, Vol. 01, No. 02, Agustus 2018 - Januari 2019 ISSN : 2620-6358

e-Journal Ekonomi Bisnis dan Akuntansi ; Merisa Fajar Aisyah ,Wiji Utami1, Sunardi, Sudarsih (2017, Volume IV (1) :131-135) Kualitas Sumber Daya Manusia, Profesionalisme Kerja, Dan Komitmen Sebagai Faktor Pendukung Peningkatan Kinerja Karyawan

I Dewa Nyoman Rai Hadiyasa, Tahun 2015 dengan judul skripsi "Pengaruh Kepemimpinan, Komunikasi dan Hubungan Industrial terhadap Semangat Kerja Karyawan

Desak Ayu Noviani, Tahun 2016 dengan judul skripsi "Pengaruh Hubungan Industrial dan Kompensasi Terhadap Kepuasan Kerja Karyawan

Kadek Trisnayanti, Tahun 2015, dengan judul Pengaruh Hubungan Industrial dan Lingkungan Kerja Fisik Terhadap Kepuasan Kerja Karyawan

Assauri Sofjan, 2002. Manajemen Pemasaran, Dasar, Konsep dan Strategi. Penerbit PT. Raja Grafindo Persada, Jakarta.

Ghozali, Imam., 2005. Aplikasi Analisis Multivariate dengan Program SPSS, Badan Penerbit Universitas Diponegoro, Semarang.
Nazir, Muhammad. (2015). Jurnal Ilmiah "Analisis Kepuasan Masyarakat mengenai Pelayanan Publik di Sistem Administrasi Manunggal Satu Atap (Samsat) Kota Samarinda". E-jurnal Ilmu Komunikasi 3(3) 14-27 FISIP Unmul.ac.id

Nur Setyaningsih. 2008. Skripsi "Analisis Indeks Kepuasan Masyarakat di Samsat Kabupaten Sragen", FISIP Universitas Diponegoro, Semarang.

Rismiati, Catur. dan Bondan Sutrisno., 2001. Pemasaran Barang dan Jasa. Penerbit Kanisius, Jakarta.

Santoso, Singgih.,2000. Buku Latihan SPSS Statistik Parametrik, Penerbit Elex Media Komputindo, Jakarta.

Santoso, Singgih dan Tjiptono, Fandi., 2001, Riset Pemasaran, Edisi Pertama, Penerbit PT Elex Media Komputindo, Jakarta.

Sanusi, Anwar. 2003. Metodologi Penelitian Praktis Untuk Ilmu Sosial dan Ekonomi. Edisi Pertama, Cetakan Pertama, Penerbit Buntara Media. Malang.

Setyawan, Hary. 2015. Jurnal ilmiah "Analisis Perbedaan Harapan dan 
Jurnal Satyagraha, Vol. 01, No. 02, Agustus 2018 - Januari 2019 ISSN : 2620-6358

Persepsi Wajib Pajak Kendaraan

Bermotor terhadap Pelayanan Publik

(Studi Kasus pada Kantor Samsat di

Kota Semarang”. E-jurnal (2015: 290-

311) FE Undip Semarang.

Sudjana, 1992. Metoda Statistika, Penerbit Tarsito, Bandung.

Sugiyono. 2004. Metode Penelitian Bisnis.

Cetakan Pertama. Penerbit CV. Alpha

Beta. Bandung.

Supranto J., 2000., Pengukuran Tingkat

Kepuasan Pelanggan. Penerbit Rineka Cipta. Jakarta.

Swasta, Basu dan Handoko, T. Hani. 2000. Manajemen Barang dalam Pemasaran. Cetakan Kedua BPFE, Yogjakarta.

Mangkunegara (2001) menguraikan bahwa "Kinerja adalah hasil kerja secara kualitas dan kuantitas yang dicapai oleh seorang pegawai dalam melaksanakan tugasnya sesuai dengan tanggung jawab yang diberikan kepadanya".

Abdurrahman Fathoni (2006) mengemukakan bahwa "Kedisiplinan adalah kesadaran dan kesediaan seseorang menaati semua peraturan perusahaan dan norma sosial yang berlaku
Manullang (2001) management yang berasal dari kata "to manage" yang mempunyai arti mengendalikan atau mengurus.

Hasibuan (2012) berpendapat bahwa "MSDM adalah ilmu dan seni mengatur hubungan dan peranan tenaga kerja agar efektif membantu terwujudnya perusahaan, karyawan, dan masyarakat.” Menurut

Handoko (2001) menjelaskan “ Manajemen sumber daya manusia adalah penarikan, seleksi, pengembangan, pemeliharaan dan penggunaan sumber daya manusia untuk mencapai baik tujuan individu maupun organisasi ". 